\title{
The most relevant diagnostic criteria for developmental dysplasia of the hip: a study of British specialists
}

\author{
Daniel Williams ${ }^{1 *}$, Evangelia Protopapa ${ }^{2}$, Kuldeep Stohr ${ }^{3}$, James B. Hunter ${ }^{4}$ and Andreas Roposch ${ }^{1,2}$
}

\begin{abstract}
Background: Developmental dysplasia of the hip $(\mathrm{DDH})$ is the most common orthopaedic disorder in newborns. Despite this considerable variation in practice exists. The aim of this study was to determine the clinical relevance and a ranking order for the diagnostic criteria in DDH amongst paediatric orthopaedic surgeons practicing in the UK.

Method: One hundred members of the British Society of Children's Orthopaedic Surgery (BSCOS) were asked to rate the importance of 37 criteria useful in the diagnosis of DDH in newborns, using a $10 \mathrm{~cm}$ visual analogue scale. We determined the consistency among specialists in rating the criteria with the intraclass correlation coefficient (ICC) and compared the results to a group of international peers.
\end{abstract}

Results: Ortolani/Barlow tests, asymmetry in abduction $\geq 20^{\circ}$ and a first-degree relative treated for DDH ranked among the top ten. Participants demonstrated poor consistency in rating the 37 criteria (ICC 0.39; $95 \%$ Cl 0.29, 0.52), but for clinical examination criteria alone their consistency improved (ICC 0.52; $0.35,0.75$ ). The importance ratings of members of BSCOS and members of the European Paediatric Orthopaedic Society differed for 15/37 (41 \%) criteria $(p<0.05)$.

Conclusions: Members of BSCOS had a preference for criteria relating to clinical examination and ultrasound.

Keywords: Developmental, Dysplasia, Hip, Diagnosis

\section{Background}

Early recognition of developmental dysplasia of the hip (DDH) associated with better outcomes [1]. Clearly defined, well formulated diagnostic criteria are vital to identify infants needing observation or treatment. This is particularly important during the first 8 weeks of life when there is perhaps greatest uncertainty as to the capacity for spontaneous resolution of abnormal findings of the hip [2-4]. In an attempt to elicit clearly defined, well-formulated diagnostic criteria for DDH in this age group, a Delphi consensus study of paediatric orthopaedic surgeons from 34 countries was conducted [5]. It identified 37 standardized diagnostic criteria for DDH in this age group. Details of criteria are shown in Additional file 1 . In the present study we sought to

\footnotetext{
* Correspondence: williams-dan@hotmail.co.uk

Investiagtion performed at UCL Institute of Child Health and Great Ormond

Street Hospital for Children, London, UK

${ }^{1}$ Department of Orthopaedic Surgery, Great Ormond Street Hospital for

Children, Great Ormond Street, London WC1N 3JH, UK

Full list of author information is available at the end of the article
}

discern the opinions of British paediatric orthopaedic surgeons on these 37 criteria. Specifically, we wanted to determine (1) a ranking order of clinical relevance of these criteria reflecting the opinions of surgeons practicing in the UK, (2) the consistency with which British paediatric orthopaedic surgeons agree about the importance of these criteria and (3) how their opinions compare to a group of international paediatric orthopaedic surgeons [6].

\section{Methods}

The study was approved by the institutional review board for Great Ormond Street Hospital and the Institute of Child Health, British Society of Children's Orthopaedic Surgery (BSCOS) and European Paediatric Orthopaedic Society (EPOS). We surveyed members of BSCOS and presented them with a set of 37 criteria grouped in 4 domains; patient history, clinical examination, ultrasonography, radiography. These had been compiled in an international consensus study [5]. We asked survey participants to rate each criterion on a $10-\mathrm{cm}$ visual analogue 
scale (VAS) for its relative importance in making the diagnosis of DDH in infants not older than 8 weeks. We defined DDH as a condition requiring either treatment or follow-up with an orthopaedic surgeon. We employed Dillman's tailored design method for survey design and conduct [7]; it entails making up to 4 contacts with participants by first-class mail or e-mail, personalized correspondence and additional contacts by telephone or fax.

We surveyed 148 eligible members of BSCOS. All surgeons in this study were specialists who examine and treat infants for DDH as part of their routine practice. We were solely interested in the surgeons' opinion on each criterion in isolation, rather than in determining how surgeons establish the diagnosis of DDH using combinations of these criteria. As such, we asked the participants to rate each of the 37 criteria irrespective of any other abnormalities. We recognize that this may not reflect how clinicians arrive at a diagnosis; however, because each criterion was rated in isolation we assumed that the relative importance rating would be stable [8]. We compiled the VAS means (a ratio scale measurement of the perceived value on the VAS provided a continuous outcome) for all criteria based on the responses of all members of BSCOS. Based on these VAS means we generated a ranking list and defined the top ten criteria. We compared VAS means to those of members of EPOS using the signed rank test at the $5 \%$ significance level.

We determined the consistency of members of BSCOS in assigning the importance rating to each criterion with the ICC. The concept of consistency is defined as the agreement of two quantitative measurements in settings where neither one is assumed correct [9]. Multiple raters evaluated all of the criteria and the case 2 model according to Shrout and Fleiss [10] was employed. ICC is interpreted as follows: $\leq 0.40$, poor consistency or large variation in opinion; 0.41 to 0.74 , acceptable consistency; and $\geq 0.75$ good consistency [11]. A sample size of 37 items with 148 raters for each criterion achieves $80 \%$ power to detect an ICC of 0.80 under the alternative hypothesis when the ICC under the null hypothesis is 0.69 , using an F-test and a $5 \%$ significance level [12].

\section{Results}

$68 \%(100 / 148)$ members of BSCOS responded to the survey. BSCOS members expressed a preference for clinical examination criteria, which constituted 6 of the top ten raking criteria (Table 1). They included Ortolani and Barlow tests, asymmetry in abduction $\geq 20^{\circ}$ and leg length discrepancy. Among the top ten ranked 3 ultrasonographic criteria: sonographically dislocatable hip, $\alpha$ angle $<45^{\circ}$, and femoral head displacement $>2 \mathrm{~mm}$ from the medial aspect of the acetabulum. A first degree relative treated for DDH was the only risk factor ranking in
Table 1 Top ten ranking criteria based on group means of BSCOS and EPOS

\begin{tabular}{|c|c|c|}
\hline Rank & $\mathrm{BSCOS}$ & EPOS \\
\hline 1 & Ortolani test positive & Ortolani test positive \\
\hline 2 & Barlow test positive & Barlow test positive \\
\hline 3 & Asymmetry in abduction $\geq 20^{\circ}$ & $\begin{array}{l}\text { Dislocatable hip on dynamic } \\
\text { ultrasound }\end{array}$ \\
\hline 4 & $\begin{array}{l}\text { Dislocatable hip on dynamic } \\
\text { ultrasound }\end{array}$ & Asymmetry in abduction $\geq 20^{\circ}$ \\
\hline 5 & Abduction limited to $45^{\circ}$ & a angle $<45^{\circ}$ \\
\hline 6 & Leg-length discrepancy/Galeazzi & $\begin{array}{l}\text { Femoral head displaced } \\
\text { on stress ultrasound }\end{array}$ \\
\hline 7 & $\begin{array}{l}\text { Any asymmetry of hip } \\
\text { abduction }\end{array}$ & $\begin{array}{l}\text { Any asymmetry of hip } \\
\text { abduction }\end{array}$ \\
\hline 8 & a angle $<45^{\circ}$ & Breech presentation \\
\hline 9 & $\begin{array}{l}\text { Femoral head displaced on } \\
\text { stress ultrasound }\end{array}$ & Abduction limited to $45^{\circ}$ \\
\hline 10 & $\begin{array}{l}\text { First degree relative treated } \\
\text { for } \mathrm{DDH}\end{array}$ & Leg-length discrepancy/Galeazzi \\
\hline
\end{tabular}

the top ten. The details for the ranking of each criteria by BSCOS members are shown in Table 2 .

VAS mean values assigned to individual criteria were largely similar between members of BSCOS and EPOS (Fig. 1). Of the 15 criteria that differed significantly, the largest differences were seen $(\mathrm{p}<0.001)$ for the criteria postural foot deformity, torticollis and abduction $\leq 70^{\circ}$, with members of BSCOS assigning higher mean ratings (Table 3).

Members of BSCOS demonstrated poor consistency in rating the 37 criteria, with an ICC of $0.39(95 \% \mathrm{CI}=0.29$, 0.52). Better consistency was found for criteria relating to the clinical examination - the ICC was $0.52(0.35,0.75)$. Members of BSCOS were least consistent in their opinions about the importance of criteria relating to hip ultrasound, with an ICC of $0.25(0.14,0.52)$. Poor consistency was noted also for criteria of patient history (ICC 0.39; $0.23,0.69)$ and radiography (ICC $0.31 ; 0.10,0.95$ ).

\section{Discussion}

This study determined the opinions of British paediatric orthopaedic surgeons about a set of 37 criteria which have been identified as the most relevant features for diagnosing DDH in the first 8 weeks of life [5]. Because all 37 criteria cannot be equally important, we wanted to delineate those identified as most and least important by British specialist surgeons and determine to what degree their opinions differ compared to specialists from other countries.

We note the potential limitations of this study. As clinical experience and exposure accumulate the symptoms and signs associated with a diagnosis are "chunked" together and not taken in isolation. By asking experts to 
Table 2 Ranking of criteria based on group means of the BSCOS members. Shown are means with standard deviations in parentheses

\begin{tabular}{|c|c|}
\hline Criterion & Mean (SD) \\
\hline \multicolumn{2}{|l|}{ Physical Examination } \\
\hline Ortolani test positive & $9.1(1.1)$ \\
\hline Barlow test positive & $8.6(1.8)$ \\
\hline Asymmetry in abduction $\geq 20^{\circ}$ & $8.4(1.7)$ \\
\hline Abduction limited to $\leq 45^{\circ}$ & $7.9(2.0)$ \\
\hline Leg-length discrepancy/Galeazzi sign & $7.9(2.7)$ \\
\hline Any asymmetry of hip abduction & $7.8(2.1)$ \\
\hline Abduction limited to $\leq 60^{\circ}$ & $6.4(2.5)$ \\
\hline Torticollis & $5.2(2.7)$ \\
\hline Abduction limited to $\leq 70^{\circ}$ & $5.2(2.8)$ \\
\hline Flexible foot deformities & $5.0(2.9)$ \\
\hline Congenital clubfoot or other fixed foot deformities & $4.0(2.8)$ \\
\hline Asymmetry of groin or skin crease(s) & $3.2(2.8)$ \\
\hline Hip click & $2.5(2.1)$ \\
\hline \multicolumn{2}{|l|}{ Ultrasound } \\
\hline Dislocatable hip (dynamic exam) & $8.1(2.5)$ \\
\hline a angle $<45^{\circ}$ (static exam) & $7.7(3.1)$ \\
\hline $\begin{array}{l}\text { Femoral head displaced anatomically with } \\
\text { no congruency on stress test }\end{array}$ & $7.6(3.2)$ \\
\hline a angle $<50^{\circ}$ (static exam) & $7.2(3.0)$ \\
\hline Femoral head coverage $\leq 45 \%$ (static exam) & $7.0(2.8)$ \\
\hline a angle $<55^{\circ}$ (static exam) & $6.4(2.8)$ \\
\hline Femoral head coverage $\leq 50 \%$ (static exam) & $6.0(2.8)$ \\
\hline a angle $<60^{\circ}$ (static exam) & $5.4(3.0)$ \\
\hline $\begin{array}{l}\text { Displacement of femoral head }>2 \mathrm{~mm} \text { from } \\
\text { medial aspect of acetabulum on dynamic exam }\end{array}$ & $4.9(3.2)$ \\
\hline Femoral head coverage $\leq 60 \%$ (static exam) & $4.3(3.1)$ \\
\hline Femoral head coverage $\leq 70 \%$ (static exam) & $3.3(3.1)$ \\
\hline \multicolumn{2}{|l|}{ Patient characteristics and history } \\
\hline First degree relative treated for $\mathrm{DDH}$ & $7.4(2.2)$ \\
\hline Breech presentation & $7.2(2.3)$ \\
\hline Breech positioning in-utero but born by vertex delivery & $5.8(2.8)$ \\
\hline Family history of DDH & $5.7(2.6)$ \\
\hline Oligohydramnios & $4.5(2.6)$ \\
\hline First born baby girl & $4.4(2.9)$ \\
\hline Female gender & $4.2(2.8)$ \\
\hline Birth weight >4000 g (8.8 lbs) & $3.4(2.5)$ \\
\hline Born by caesarian section & $3.2(2.6)$ \\
\hline Multiparous mother & $3.1(2.7)$ \\
\hline \multicolumn{2}{|l|}{ Radiography } \\
\hline Midpoint of the femoral metaphysis lateral to Perkins line & $4.6(3.5)$ \\
\hline Acetabular index $>30^{\circ}$ at 8 weeks & $2.7(2.8)$ \\
\hline Acetabular index $>25^{\circ}$ at 8 weeks & $2.0(2.3)$ \\
\hline
\end{tabular}

rank individual criteria we have established the opinions of surgeons and this may not reflect their normal practice. However, individual criteria are important as they can act as a trigger to activate the relevant knowledge.

Surveys are an effective means of evaluating physicians' attitudes [13] and evidence suggests that physicians act as they indicate in surveys [14]. The response rate of this survey was $68 \%$, however, this is reasonable considering that the mean response rate of surveys involving physicians is $54 \%$ [15].

Members of BSCOS rated historically well-established diagnostic criteria such as the Ortolani test highest and controversial ones such as hip click lowest despite this being a common reason for referral. The opinions of British surgeons were consistent with an international group of paediatric orthopaedic surgeons - the top ten ranking criteria were identical with the exception that breech presentation was not included in the top-ten of the BSCOS panellists. The pattern of importance ratings was almost identical between BSCOS and EPOS (Fig. 1).

The fact that criteria related to the clinical examination were among the highest ranking in this study reflects other studies from the UK about the diagnosis of DDH in early infancy. Clarke et al. [16] based triage decisions of infants not older than 3 days on Ortolani, Barlow and Galeazzi tests. Talbot et al. [17] and Price et al. [18], examining the same age group, used Ortolani and Barlow tests but placed no emphasis on the Galeazzi test. Limited hip abduction was not reported as a diagnostic criterion in either of these 3 large studies. However, limited abduction $\geq 20^{\circ}$ ranked third amongst BSCOS members. In fact, 3 criteria relating to hip abduction ranked top ten in our study; asymmetry in abduction $\geq 20^{\circ}$, abduction limited to $45^{\circ}$ and any asymmetry in abduction. In contrast, a study of infants aged 3 to 10 months highlights the lack of reliability when relying on clinical examination alone, with $46 \%$ of infants without DDH exhibiting a limit to hip abduction [19]. Of note, members of EPOS placed less value on the criterion hip abduction.

In terms of risk factors, members of BSCOS ranked highest family history and breech presentation (Table 2). This is in keeping with current practice: 3 recent studies on screening in DDH [16-18] utilized these 2 criteria to select at-risk patients prompting specialist referrals. In a study of 64670 births, Talbot et al. [17] evaluated the incidence of $\mathrm{DDH}$ in patients with these 2 risk factors; the incidence was $3.2 \%$ with a family history of DDH and $2.5 \%$ with a breech presentation. Price et al. [20] examined, amongst others, the risk factors oligohydramnios and foot deformity but did not comment on their associations with $\mathrm{DDH}$, suggesting that they had little value in predicting DDH. This is consistent with our survey these 2 criteria are among the lowest ranking. 


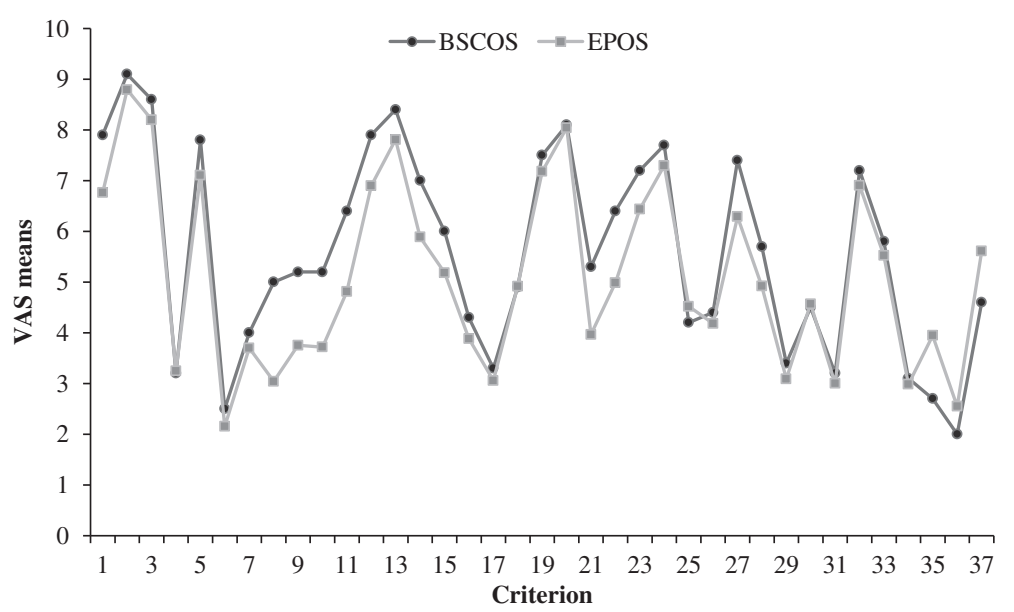

Fig. 1 Comparison of mean ratings of EPOS and BSCOS. Details of criteria are shown in Additional file 1

While our study showed that members of BSCOS regarded ultrasound criteria as important in general, it also confirmed the ongoing controversy $[2,21]$ about the nature of ultrasound criteria. Three recent studies about hip screening showed that the ultrasound criteria by which surgeons defined DDH varied in the UK. While one study [16] utilized criteria based on dynamic ultrasound, another study [17] relied on the $\alpha$ angle in combination with dynamic criteria, and a third study [18] relied solely on the $\alpha$ angle. Our survey reflected this controversy - a dislocatable hip seen on dynamic

Table 315 criteria based on VAS ratings with a statistically significant difference between BSCOS and EPOS respondents. Shown are means and standard deviations

\begin{tabular}{llll}
\hline Criterion & $\begin{array}{l}\text { BSCOS } \\
(n=85)\end{array}$ & $\begin{array}{l}\text { EPOS } \\
(n=156)\end{array}$ & $p$-value \\
\hline Leg-length discrepancy/Galeazzi sign & $7.9(2.7)$ & $6.8(3.0)$ & 0.001 \\
Any asymmetry of hip abduction & $7.8(2.1)$ & $7.1(2.5)$ & 0.017 \\
Flexible foot deformities & $5.0(2.9)$ & $3.0(2.5)$ & $<0.001$ \\
Torticollis & $5.2(2.7)$ & $3.7(2.5)$ & $<0.001$ \\
Abduction limited to $\leq 70^{\circ}$ & $5.2(2.8)$ & $3.7(2.8)$ & $<0.001$ \\
Abduction limited to $\leq 60^{\circ}$ & $6.4(2.5)$ & $4.8(2.7)$ & $<0.001$ \\
Abduction limited to $45^{\circ}$ & $7.9(2.0)$ & $6.9(2.5)$ & 0.001 \\
Asymmetry in abduction $\geq 20^{\circ}$ & $8.4(1.7)$ & $7.8(2.4)$ & 0.019 \\
Femoral head coverage $\leq 45 \%$ & $7.0(2.8)$ & $5.9(3.4)$ & 0.001 \\
a angle $<60^{\circ}$ & $5.3(2.9)$ & $4.0(3.2)$ & 0.002 \\
a angle $<55^{\circ}$ & $6.4(2.8)$ & $5.0(3.2)$ & 0.045 \\
First degree relative treated for DDH & $7.4(2.2)$ & $6.3(2.6)$ & 0.002 \\
Any family history of DDH & $5.7(2.6)$ & $4.9(2.8)$ & 0.044 \\
Acetabular index $>30^{\circ}$ at 8 weeks & $2.7(2.8)$ & $3.9(3.1)$ & 0.006 \\
Midpoint of the femoral metaphysis & $4.6(3.5)$ & $5.6(3.3)$ & 0.047 \\
lateral to Perkins line & & & \\
\hline
\end{tabular}

ultrasound and an $\alpha$ angle $<45^{\circ}$ ranked among the top ten criteria, similar to the opinions of members of EPOS, but also the femoral head coverage as measured by ultrasound was rated highly (Table 2 ).

In quantifying how consistent members of BSCOS were in rating the 37 criteria we used the ICC. It provides a measure of the extent to which any single member identified at random would compare to any other randomly selected member. Coefficients for judgments on individual patients should reach values of 0.70 to 0.80 [22]. The best value that members of BSCOS reached was 0.52 , indicating acceptable agreement about clinical examination criteria. Similar patterns were seen in an international study where paediatric orthopaedic surgeons were most consistent about clinical examination criteria [6]. In contrast, for criteria relating to patient history, ultrasound and radiography, large variations in the opinions of UK surgeons were seen. Members of BSCOS were least consistent about the ultrasonographic criteria; this may be related to the inconsistent evidence in terms of the use of this diagnostic modality. It also reflects current practice in the UK: 3 recent studies about hip screening employed different ultrasonographic criteria in defining DDH [16-18].

\section{Conclusion}

The ranking order of criteria generated in this survey offers information for clinicians in primary and secondary care about the opinions of expert diagnosticians. Clinicians can determine how their personal preferences for diagnostic criteria differ from those experts. Such a comparison may reassure clinicians that their practice is mirrored by others, or, if not, can provide a basis for reconsidering their practice. 


\section{Additional file}

Additional file 1: 37 diagnostic criteria for developmental dysplasia of the hip in children less than 8 weeks old. (DOCX $106 \mathrm{~kb}$ )

\section{Abbreviations}

DDH: Developmental dysplasia of the hip; BSCOS: British society of children's orthopaedic surgery; ICC: Intraclass correlation coefficient; EPOS: European paediatric orthopaedic society; VAS: Visual analogue scale.

\section{Competing interests}

The authors declare that they have no competing interests.

\section{Authors' contributions}

DW: data analysis, interpretation of data, drafting and revisions of the manuscript. KS: data collection, critical appraisal and interpretation of data and manuscript. EP: data collection and statistical analysis, drafting and critical revision of the manuscript. JH: interpretation of data, critical review of manuscript. AR: conception and design of study, supervision of statistical analysis \& drafting of manuscript; critical revisions of manuscript. All authors read and approved the manuscript.

\section{Acknowledgements}

All phases of this study were supported by grants from BUPA foundation and Great Ormond Street Hospital Children's Charity. We would like to thank all of the BSCOS surgeons who contributed to this study.

\section{Author details}

'Department of Orthopaedic Surgery, Great Ormond Street Hospital for Children, Great Ormond Street, London WC1N 3JH, UK. ${ }^{2}$ Institute of Child Health, University College, London, UK. ${ }^{3}$ Addenbrooke's Hospital, Cambridge, UK. ${ }^{4}$ Nottingham University Hospital, Nottingham, UK.

\section{Received: 21 August 2015 Accepted: 5 January 2016}

\section{Published online: 19 January 2016}

\section{References}

1. Weinstein SL, Mubarak SJ, Wenger DR. Developmental hip dysplasia and dislocation: Part II. Instr Course Lect. 2004;53:531-42.

2. Roposch A, Moreau NM, Uleryk E, Doria AS. Developmental dysplasia of the hip: quality of reporting of diagnostic accuracy for US. Radiology. 2006;241: 854-60.

3. Roposch A, Wright JG. Increased diagnostic information and understanding disease: uncertainty in the diagnosis of developmental hip dysplasia. Radiology. 2007;242:355-9.

4. Woolacott NF, Puhan MA, Steurer J, Kleijnen J. Ultrasonography in screening for developmental dysplasia of the hip in newborns: systematic review. BMJ. 2005:330:1413.

5. Roposch A, Liu LQ, Hefti F, Clarke NM, Wedge JH. Standardized diagnostic criteria for developmental dysplasia of the hip in early infancy. Clin Orthop Relat Res. 2011;469:3451-61.

6. Roposch A, Liu LQ, Protopapa E. Variations in the use of diagnostic criteria for developmental dysplasia of the hip. Clin Orthop Relat Res. 2013;471:1946-54.

7. Dillman DA. Mail and internet surveys: the tailored design method. 2nd ed. New York: Wiley; 2000

8. Graham B, Regehr G, Wright JG. Delphi as a method to establish consensus for diagnostic criteria. J Clin Epidemiol. 2003;56:1150-6.

9. Newman-Toker DE, Pronovost PJ. Diagnostic errors-the next frontier for patient safety. JAMA. 2009;301:1060-2.

10. Shrout PE, Fleiss JL. Intraclass correlations: Uses in assessing rater reliability. Psychol Bulletin. 1979;86:420-7.

11. Portney LG, Watkinks MP. Statistical measures of reliability. In: Foundations of clinical research: applications in practice. 2nd ed. Princeton: Princteon-Hall; 2000.

12. Walter SD, Eliasziw M, Donner A. Sample size and optimal designs for reliability studies. Stat Med. 1998:17:101-10.

13. Epstein AM, McNeil BJ. Relationship beliefs and behavior in test ordering Am J Med. 1986:80:865-70.

14. Moskowitz AJ, Kuipers BJ, Kassirer JP. Dealing with uncertainty, risks, and tradeoffs in clinical decisions: a cognitive science approach. Ann Intern Med. 1988; 108:435-49.
15. Kellerman SE, Herold J. Physician Response to Surveys: A Review of the Literature. Am J Prev Med. 2001:20:61-7.

16. Clarke NMP, Reading IC, Corbin C, Taylor CC, Bochmann T. Twenty years' experience of selective secondary ultrasound screening for congenital dislocation of the hip. Arch Dis Child. 2012;97:423-9.

17. Talbot $\mathrm{CL}$, Paton RW. Screening of selected risk factors in developmental dysplasia of the hip: an observational study. Arch Dis Child. 2013;98:692-6.

18. Price KR, Dove R, Hunter JB. The use of X-ray at 5 months in a selective screening programme for developmental dysplasia of the hip. J Child Orthop. 2011;5:195-200.

19. Castelein RM, Korte J. Limited hip abduction in the infant. J Pediatr Orthop. 2001;21:668-70

20. Price KR, Dove R, Hunter JB. Current screening recommendations for developmental dysplasia of the hip may lead to an increase in open reduction. Bone Joint J. 2013;95-B:846-50.

21. Sucato DJ, Johnston CE, Birch JG, Herring JA, Mack P. Outcome of ultrasonographic hip abnormalities in clinically stable hips. J Pediatr Orthop. 1999;19:754-9.

22. Bland JM, Altman DG. Cronbach's alpha. BMJ. 1997;314:572.
Submit your next manuscript to BioMed Central and we will help you at every step:

- We accept pre-submission inquiries

- Our selector tool helps you to find the most relevant journal

- We provide round the clock customer support

- Convenient online submission

- Thorough peer review

- Inclusion in PubMed and all major indexing services

- Maximum visibility for your research

Submit your manuscript at www.biomedcentral.com/submit 